\title{
Refractory Childhood Spinal Cord Neoplasm
}

National Cancer Institute

\section{Source}

National Cancer Institute. Refractory Childhood Spinal Cord Neoplasm. NCI Thesaurus.

Code C71714.

Spinal cord neoplasm in childhood which is resistant to treatment. 